\title{
High levels of Epstein-Barr virus in COPD
}

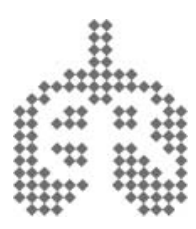

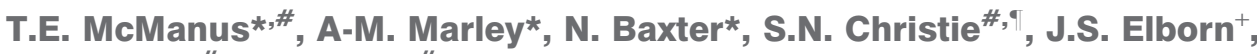 \\ H.J. O'Neill ${ }^{\#}$, P.V. Coyle ${ }^{\#}$ and J.C. Kidney*
}

ABSTRACT: Latent viral infection has been implicated in the pathophysiology of chronic obstructive pulmonary disease (COPD). Epstein-Barr virus (EBV) is known to be important in pulmonary fibrosis. The current authors hypothesised that EBV is associated with the pathogenesis of COPD.

Sputum samples were collected from patients both during exacerbations of COPD and when stable. A control group of smokers who did not have airways obstruction also had their sputum examined. The presence of EBV DNA was established and quantified using a real-time nucleic acid amplification assay.

A total of 136 patients with COPD were recruited during an acute exacerbation and a total of 68 when stable. EBV was detected in 65 (48\%) exacerbation cases and 31 (46\%) stable patients. In the comparison group of 16 nonobstructed smokers, EBV was demonstrated in only one (6\%) case. Risk of COPD in patients with EBV and who are smokers confers an odds ratio of 12.6.

Epstein-Barr virus DNA is more frequently identified in the respiratory tract of chronic obstructive pulmonary disease patients in comparison with unaffected smokers. It is present both during exacerbation and when stable, suggesting that infection is persistent. Smokers who do not develop chronic obstructive pulmonary disease rarely have Epstein-Barr virus in their sputum. This finding may be of importance in the pathogenesis of chronic obstructive pulmonary disease.

KEYWORDS: Chronic obstructive pulmonary disease, Epstein-Barr virus, latent viral infection, pathogenesis, real-time PCR

hronic obstructive pulmonary disease (COPD) is characterised by an inflamed airway with neutrophil accumulation in the airway [1]. The airway mucosa is infiltrated with cytotoxic T-lymphocytes (CD8+) [2]. This has led to the hypothesis that an additional agent other than smoking is required to develop COPD. Chronic viral infection could account for the CD8+ T-cells and the differentiation between smokers with and without COPD. The role of acute respiratory viral infection in COPD exacerbations has recently emerged [3, 4]. Molecular diagnostic techniques allow investigators to study the role of latent viral infections in the pathogenesis of COPD. Some studies have suggested that a latent virus is important in the pathogenesis of COPD [5].

Epstein-Barr virus (EBV) is a member of the herpes virus family, which is widespread and has been associated with a variety of disease processes, including glandular fever, Burkitt's lymphoma, nasopharyngeal carcinoma, lymphoma and post-transplant lymphoproliferative disease [6-9]. Burkitt's lymphoma and nasopharyngeal carcinoma are both associated with latent EBV infection [10, 11]. Patients with HIV who have EBV are more likely to develop a lymphoma as their disease progresses. Suppression of this virus with acyclovir or similar agents with anti-EBV activity reduces the incidence of non-Hodgkin's lymphoma in patients with AIDS, suggesting a causal role in the viral pathogenesis of AIDSrelated lymphoma [12].

EBV has been identified in the lower airways and is seen within exfoliated epithelial cells using in situ hybridisation [13]. EBV has also been frequently found in the lungs in pulmonary fibrosis [14]. KelLy et al. [14] analysed lung biopsies and blood samples from patients with idiopathic pulmonary fibrosis and found EBV in $\sim 60 \%$ of cases but in none of the lung transplant patient controls. Further investigation, using immunohistochemistry, has shown that the virus was located primarily in the airway epithelial cells [15].

Sputum is a rich source of airway epithelial cells; the present authors undertook a study to examine
AFFILIATIONS

*Dept of Respiratory Medicine, Mater Hospital,

\#Regional Virus Laboratory, Kelvin Building, Royal Victoria Hospital, "Royal Belfast Hospital for Sick Children, and

'Dept of Respiratory Medicine, Belfast City Hospital, Belfast, UK.

CORRESPONDENCE

T.E. McManus

Dept of Respiratory Medicine

Mater Hospital

Belfast BT14 6AB

UK

Fax: 442890634803

E-mail: TerryMcManus@

doctors.org.uk

Received:

August 152007

Accepted after revision:

February 072008

STATEMENT OF INTEREST

A statement of interest for this study can be found at

www.erj.ersjournals.com/misc/

statements.shtml 
sputum for viruses. Samples were examined during exacerbation and remission, as well as in a control group of healthy smokers. It was hypothesised that EBV was a possible candidate for persistent viral infection in COPD.

\section{MATERIALS AND METHODS \\ Study subjects}

Subjects with COPD were recruited over a 2-yr period. COPD was defined using the Global Initiative for Chronic Obstructive Lung Disease (GOLD) criteria [16]. An exacerbated group were recruited when attending hospital, within $24 \mathrm{~h}$ of presentation. Stable COPD patients (no increase in respiratory symptoms or treatment for the previous 8 weeks) were also recruited as were a control group who had smoked but who did not have any evidence of airways obstruction. Spirometry (MicroLab 3300 spirometer; Micro Medical Ltd, Gillingham, UK) pre- and post-bronchodilator therapy $(2.5 \mathrm{mg}$ salbutamol nebulised; Allen \& Hanbury, London, UK) was performed. Patients who had significant improvement following bronchodilator therapy ( $\geqslant 200 \mathrm{~mL}$ or $+15 \%$ ) were excluded. Those patients with a history of bronchiectasis, a neoplastic process or other serious concomitant disease were excluded. The present study was approved by the research ethics committee of Queen's University Belfast, Belfast, UK.

\section{Study design}

The present study was designed on known prevalence of acute respiratory infections [16, 17]. For a detection rate of $30 \%$ in exacerbation and $10 \%$ when stable, using a power of 0.8 and significance at 0.05 , the present authors calculated that 128 patients would be needed during exacerbation and 64 stable patients with COPD. Using a prevalence of $50 \%$ in the disease group [18] and EBV detection at $4 \%$ in the nondiseased group [19], it was calculated that the control group using a $4: 1$ ratio would require 64 stable COPD patients and 16 nonobstructed smokers.

\section{Methods}

Sputum samples

Sputum was obtained either by spontaneous production or by induction with hypertonic ( $3 \%$ ) saline nebulised through an air driven nebuliser (Micro Mist ${ }$ small volume nebuliser; Hudson Respiratory Care Inc., Ashby-de-la-Zouch, UK) for $20 \mathrm{~min}$. Forced expiratory volume in one second (FEV1) was repeated every $5 \mathrm{~min}$. The procedure was stopped if there was a $20 \%$ fall in FEV1. Sputum induction was not used in acute exacerbations of COPD.

Sputum samples had plugs removed from saliva. Specimens were mixed with four volumes $0.1 \%$ dithiothreitol (Sigma, Poole, UK) and shaken in an orbital incubator (Gallenkamp, Loughborough, UK) for $15 \mathrm{~min}$ at $37^{\circ} \mathrm{C}$ followed by the addition of four volumes of PBS and shaken for a further $5 \mathrm{~min}$. The resulting suspension was then filtered through a 50$\mu \mathrm{m}$ nylon gauze (Lockertex, Warrington, UK) and spun down at $1,000 \times g$ for $10 \mathrm{~min}$. After removing the supernatant, the cell pellet was resuspended in lysis buffer (QIAamp DNA Blood Mini Kit; Qiagen, Crawley, UK). Total nucleic acid extraction was performed on $200 \mu \mathrm{L}$ of sputum sample suspended in lysis buffer. A separate sample was resuspended in PBS, a total and epithelial cell count was performed using the glass cover slip method as previously described [20].

\section{PCR: GAPDH}

Glyceraldehyde-3-phosphate dehydrogenase (GAPDH) was employed as a reference housekeeping gene. A published primer and probe set were used, combined with a set of external primers designed using primer design software (PrimerSelect 5.00, 1993-2001; DNASTAR Inc., Konstanz, Germany) [21]. Following nucleic acid extraction (Qiagen QIAamp DNA Blood Mini Kit), $2 \mu \mathrm{L}$ of each specimen was combined with $8 \mu \mathrm{L}$ of GAPDH mastermix.

First-round PCR was performed on a thermal cycler (MJ Research; Peltier Thermal Cycler, San Francisco, CA, USA) and $0.2 \mu \mathrm{L}$ of the first-round product was then used in combination with $9.8 \mu \mathrm{L}$ of mastermix containing primers and a TaqMan ${ }^{\circledR}$ probe (labelled with 6-carboxyfluorescein and 6-carboxytetramethylrhodamine dyes) internal to the first round primers. Real-time PCR (30 cycles) was carried out on a LightCycler (Roche Diagnostics Corporation, Mannheim, Germany) with log dilutions of the cloned target sequence being used as calibrators for quantitation of specimen copy numbers.
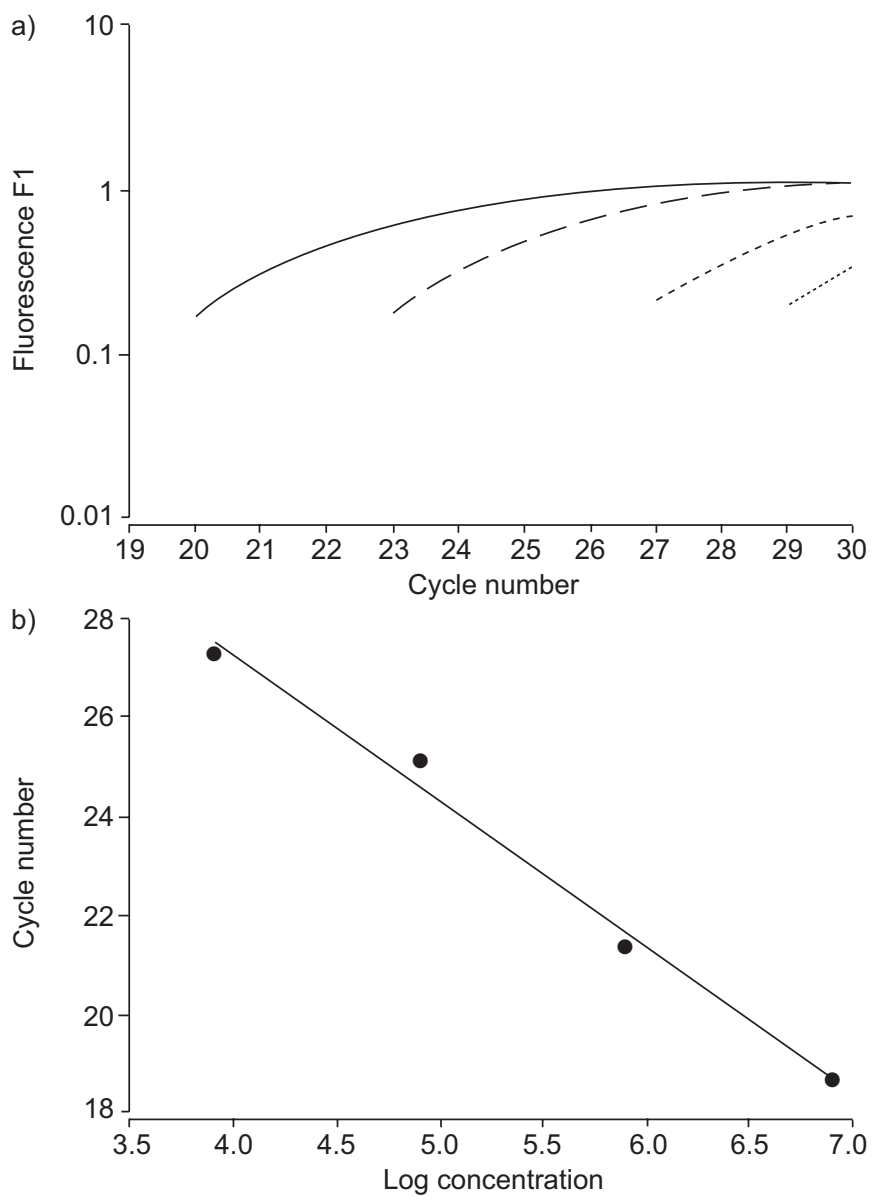

FIGURE 1. Graphs showing a) real-time PCR of serial log dilutions of EpsteinBarr virus (EBV)-cloned specimens at fluorescence intensity $F 1$ and b) the corresponding standard curve created from serial log dilutions of EBV (slope= -2.928 , intercept $=38.94$, error $=0.148, r=-1.000$ ) . a) $\longrightarrow$ : EBV dilution $\times 10^{-5}$; ---- : EBV dilution $\times 10^{-6}$; ------: EBV dilution $\times 10^{-7} ; \cdots \cdots \cdots \cdot$. EBV dilution $\times 10^{-8}$ b) ——: linear regression curve; $\bullet$ : crossing points. 


\section{PCR: EBV}

All specimens were screened for copy numbers of EBV BNRF 1 gene using real-time PCR. The EBV primers and probe used have been published previously, a second set of primers external to these were designed "in house" (H.J. O'Neill) to make a nested assay [22]. All primers and probes are listed in supplementary table SI, all mastermixes are listed in supplementary table SII and all cycling conditions are listed in table SIII. All EBV copy numbers stated have been adjusted for GAPDH copy numbers. The normalisation procedure used was a ratio between EBV and GAPDH copy numbers. All specimens were also tested for EBV using a gel-based nested PCR assay that was quality controlled and used for the routine screening of National Health Service (UK) clinical specimens.

\section{Quantitation}

Cloned samples of each assay target were prepared using pCR 2.1-TOPO ${ }_{\circledR}$ plasmid vector (Invitrogen, Paisley, UK). The target sequence identity was confirmed by sequencing (ALFexpress II DNA analyser; Amersham Biosciences, Amersham, UK) and performing a BLAST search with resulting $>99 \%$ homology for the GAPDH and EBV gene sequences. The GAPDH and EBV LightCycler assays (fig. 1) had detection limits of five and six copies per reaction, respectively.

\section{Analysis}

Normally distributed data were presented as mean \pm SD. Nonparametric data were expressed as median and interquartile ranges. Normally distributed continuous variables were compared by an unpaired t-test; otherwise the differences were assessed by the Mann-Whitney U-test. For discrete variables, frequencies and percentages were reported and groups compared using the Chi-squared test. Correlations were performed using Spearman's rank correlation. A significance level of $5 \%$ was chosen. In cases of multiple comparisons, logistical regression was performed.

\section{RESULTS}

In total, 136 patients were recruited during an acute exacerbation of COPD. In addition, 68 COPD patients were recruited when stable; 33 of these were seen both during an exacerbation and during remission. In addition, 16 subjects who smoked and did not have airflow obstruction were also studied (table 1). The male/female ratio distribution between groups was not significantly different $(p=0.24)$. GAPDH was present in all extracted specimens, confirming that sputum specimens contained cellular material in every case. All cases in which EBV was detected by quantitation were confirmed as being EBV positive using the nested gel-based PCR assay.

EBV was seen more frequently in patients with a history of COPD, both during exacerbations (65 (48\%) positive patients; $\mathrm{p}<0.05)$ and whilst stable $(31(46 \%)$ positive patients; $\mathrm{p}<0.05)$ than in nonobstructed smokers, where one $(6 \%)$ patient was positive (table 2). Risk of COPD in patients with EBV who were smokers conferred an odds ratio of 12.6.

EBV copy numbers were measured as 4.08 and 4.71 copies per reaction (log) during exacerbation and stable states, respectively. Also, in the group of patients who were reviewed, EBV copy numbers were measured as 4.01 and 4.74 copies per reaction (log) during exacerbation and stable states, respectively.

There was no relationship between the detection of EBV and smoking history (pack-yrs/smoking status) or lung function

\section{TABLE I Patient demographics and PCR assay results}

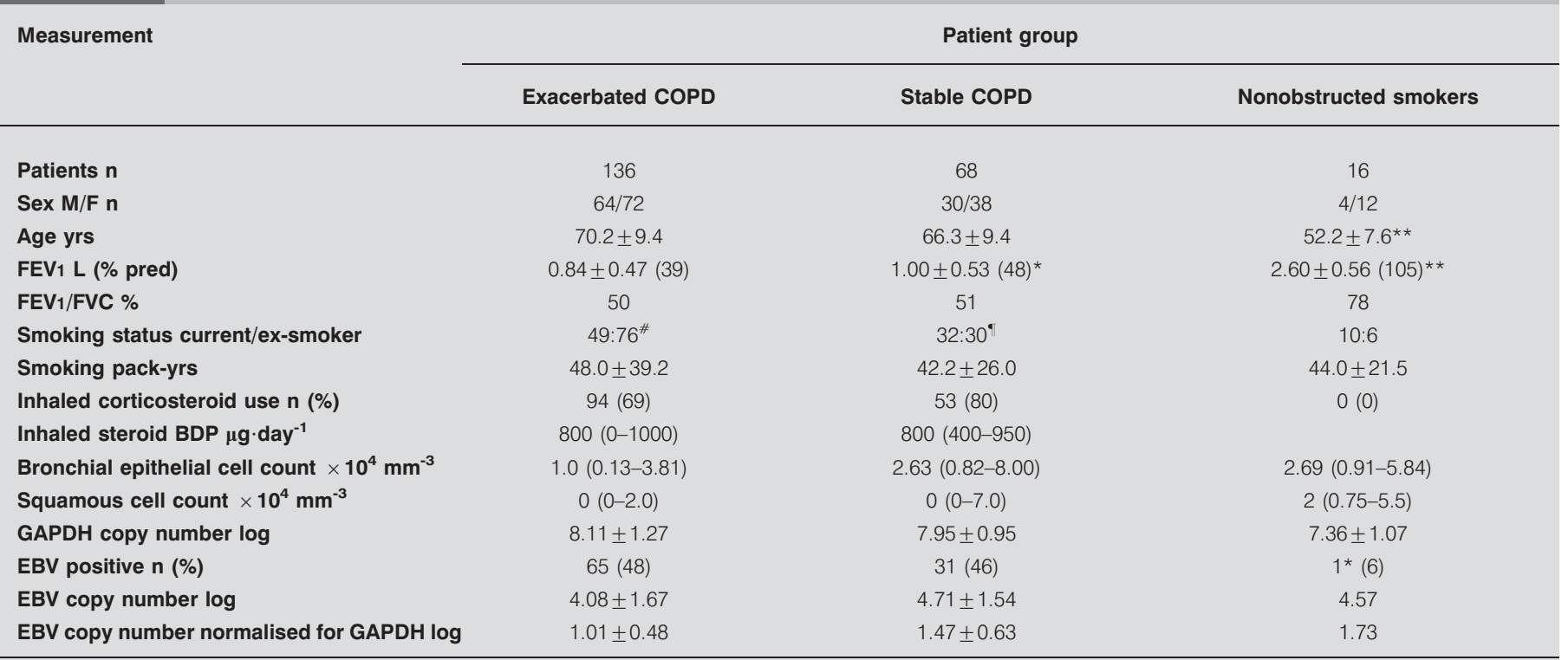

Data are presented as mean $\pm \mathrm{SD}$ or median (interquartile range), unless otherwise stated. COPD: chronic obstructive pulmonary disease; M: male; F: female; FEV 1 forced expiratory volume in one second; \% pred: \% predicted; FVC: forced vital capacity; BDP: beclomethasone dipropionate (or equivalent); GADPH: reduced glyceraldehydes phosphate dehydrogenase; EBV: Epstein-Barr virus. ${ }^{*}$ : excluding 11 subjects who were lifelong smokers; ": excluding six subjects who were lifelong smokers. *: $p<0.05 ;{ }^{* *}: p<0.01$. 


\begin{tabular}{lccc} 
TABLE 2 & $\begin{array}{l}\text { Comparison of Epstein-Barr virus infection } \\
\text { between groups }\end{array}$ & p-value \\
\hline Groups & OR $\mathbf{( 9 5 \% ~} \mathbf{~ I )}$ & $\begin{array}{c}\text { Relative risk } \\
\mathbf{( 9 5 \% ~ C l )}\end{array}$ & \\
\hline $\begin{array}{l}\text { Exacerbated versus } \\
\text { stable }\end{array}$ & $1.1(0.6-2.0)$ & $1.1(0.8-1.4)$ & 0.77 \\
$\begin{array}{l}\text { Stable versus NOS } \\
\text { Exacerbated versus } \\
\text { NOS }\end{array}$ & $12.6(1.6-269.2)$ & $7.3(1.1-49.5)$ & 0.0036 \\
\hline
\end{tabular}

OR: odds ratio; Cl: confidence interval; NOS: nonobstructed smokers. ${ }^{*}$ : NOS patients who have smoked but who have normal spirometry

(FEV1 \% predicted) within any of the three groups. Similarly no correlations between EBV copy number and smoking history or lung function were seen. The use of inhaled steroids was also examined (both in individual groups and as overall terms on combination of all groups), but no association with EBV detection was seen. Patients' lung function improved significantly following treatment of exacerbations, with mean FEV1 increasing from $0.84-1.00 \mathrm{~L}$. No association was seen between the severity of airways disease as determined by GOLD criteria and the detection of EBV. The EBV copy number correlated significantly with the number of epithelial cells seen in sputum specimens in COPD $(p<0.005)$. There was no difference in positive/negative EBV detection rates on correlation with EBV copy number. There were similar numbers of epithelial cells in sputum samples from COPD patients when compared with those from nonobstructed smokers. There were no correlations seen between EBV copy number and total or differential white cell counts. There was evidence of viral persistence on follow-up testing (tables 3 and 4). Of the 19 EBV-positive cases, 15 (58\% of the total 33 patients with exacerbated COPD) remained positive on repeat testing. Four cases went from testing EBV positive to negative and four cases also went from testing EBV negative to positive. No significant correlations were seen between age and positive EBV detection/copy number of EBV in sputum.

\section{DISCUSSION}

In the present study, a significantly increased incidence of EBV was identified in patients with COPD. EBV was also found in high copy numbers in stable COPD, but was not significantly different on comparison with exacerbated patients. During an exacerbation, when mucus and leukocyte recruitment is increased to the airway [23], there was a reduction in the copies of EBV from 4.71 to 4.08 copies per reaction (log) although this was not statistically significant $(p=0.09)$. This does show, however, that EBV is not behaving like a latent virus that arises during exacerbation and eventually clears from the airway, but that it persists. The variation in EBV detection between exacerbation and stable state in those patients who were sampled at both time-points suggests that there is a degree of variation in virus replication.

The lack of correlation between EBV copy number and lung function, severity of disease as assessed by GOLD criteria or total/differential white cells counts may be a reflection of the study size. The present study sought to determine an association between the presence of EBV airway infection and COPD. Having identified an association, it is a separate issue to analyse potential associations with the above variables. As demonstrated in previous COPD population studies, very large sample numbers are required in order to test a hypothesis in relation to differences in variables, such as lung function.

The findings of the present study are based on PCR assay results; PCR directly detects virus DNA and implicates active virus replication, based on the assumption that if the virus is detectable then it represents actively produced virus. In the clinical setting, EBV detection is usually associated only with related disease processes and their manifestations [24]. Due to the difficulty in culturing EBV, culture as a back-up methodology is not practicable. The quantitative molecular amplification described herein is now regarded as the gold standard for detecting replicating virus [25]. EBV can infect subjects resulting in acute, persistent and latent viral infections [26]. The EBV BCRF-1 protein is very similar to human interleukin10, which has anti-inflammatory actions. This feature may result in reduced viral clearance and viral persistence [27].

\section{TABLE 3 Persistence of Epstein-Barr virus (EBV) infection}

Measurement

Exacerbated COPD

Patient group

\section{3}

$0.82 \pm 0.38(39)$

50

$42 \pm 27$

$400(0-800)$

$19(58)$

$4.01 \pm 1.52$

$1.00 \pm 0.43$

Same patients reviewed

33

$0.91 \pm 0.41(48)$

55

$800(200-1000)$

19 (58)

$4.74 \pm 1.56$

$1.28 \pm 0.49$

Data are presented as mean \pm SD or median (interquartile range), unless otherwise stated. COPD: chronic obstructive pulmonary disease; FEV1: forced expiratory volume in one second; \% pred: \% predicted; FVC: forced vital capacity; BDP: beclomethasone diapropionate; GAPDH: reduced glyceraldehydes phosphate dehydrogenase. 


\begin{tabular}{lc} 
TABLE 4 & $\begin{array}{l}\text { Status of Epstein-Barr virus } \\
\text { between samples }\end{array}$ \\
\hline EBV status between samples & Patients $\mathbf{n}(\%)$ \\
\hline Negative $\rightarrow$ negative & $10(30)$ \\
Negative $\rightarrow$ positive & $4(12)$ \\
Positive $\rightarrow$ positive & $15(46)$ \\
Positive $\rightarrow$ negative & $4(12)$ \\
\hline
\end{tabular}

It is also possible that EBV may potentiate viral infection in COPD patients. This mechanism would involve enhanced virus survival and an impaired interferon- $\gamma$ host response. EBV latent membrane protein (LMP) 1 stops the activation of CD8+ T-cells in nasopharyngeal carcinoma (NPC) and correlates with Fas ligand and caspase-3 expression. LMP1 was shown to enhance survival and proliferation related signals in NPC [28]. EBV-specific CD8(+) T-cells, which predominantly express the memory phenotype, did not express the CXC chemokine receptor 1 [29]. Immunoglobulin-like transcript-2 is expressed in $40-55 \%$ of EBV-specific CD8 T-cells in healthy patients, and its expression is increased on antiviral CD8 cells in chronic infection, which suppresses interferon- $\gamma$ production; in doing so, this may interfere with protective CD8 T-cell function [30]. Thus, chronic EBV infection may lead to impaired interferon- $\gamma$ production and, in turn, a reduced innate immune response characterised by recurrent viral and bacterial infection. The finding of a correlation between the EBV copy number and epithelial cell count supports the hypothesis that EBV is being shed by the airway epithelial cells rather than being trafficked into the airway with an inflammatory cell infiltrate.

In conclusion, Epstein-Barr virus is frequently detected in the sputum from patients with chronic obstructive pulmonary disease, whilst it is uncommon in smoking patients who have normal spirometry. These findings suggest that Epstein-Barr virus may be related to the development of chronic obstructive pulmonary disease.

\section{ACKNOWLEDGEMENTS}

The authors acknowledge the assistance of the staff and patients of Mater Hospital, Belfast, UK.

\section{REFERENCES}

1 Peleman RA, Rytila PH, Kips JC, Joos GF, Pauwels RA. The cellular composition of induced sputum in chronic obstructive pulmonary disease. Eur Respir J 1999; 13: 839-843.

2 Saetta M, Baraldo S, Corbino L, et al. CD8+ve cells in the lungs of smokers with chronic obstructive pulmonary disease. Am J Respir Crit Care Med 1999; 160: 711-717.

3 Rohde G, Wiethege A, Borg I, et al. Respiratory viruses in exacerbations of chronic obstructive pulmonary disease requiring hospitalisation: a case-control study. Thorax 2003; 58: $37-42$.

4 Seemungal T, Harper-Owen R, Bhowmik A, et al. Respiratory viruses, symptoms, and inflammatory markers in acute exacerbations and stable chronic obstructive pulmonary disease. Am J Respir Crit Care Med 2001; 164: 1618-1623.

5 Matsuse T, Hayashi S, Kuwano K, Keunecke H, Jefferies WA, Hogg JC. Latent adenoviral infection in the pathogenesis of chronic airways obstruction. Am Rev Respir Dis 1992; 146: 177-184.

6 Niller HH, Salamon D, Ilg K, et al. EBV-associated neoplasms: alternative pathogenetic pathways. Med Hypotheses 2004; 62: 387-391.

7 Stewart JP, Egan JJ, Ross AJ, et al. The detection of EpsteinBarr virus DNA in lung tissue from patients with idiopathic pulmonary fibrosis. Am J Respir Crit Care Med 1999; 159: 1336-1341.

8 Grogan E, Jenson H, Countryman J, Heston L, Gradoville L, Miller G. Transfection of a rearranged viral DNA fragment, WZhet, stably converts latent Epstein-Barr viral infection to productive infection in lymphoid cells. Proc Natl Acad Sci USA 1987; 84: 1332-1336.

9 Hammerschmidt W, Sugden B. Identification and characterization of oriLyt, a lytic origin of DNA replication of Epstein-Barr virus. Cell 1988; 55: 427-433.

10 Epstein MA, Achong BG, Barr YM. Virus particles in cultured lymphoblasts from Burkitt's lymphoma. Lancet 1964; 15: 702-703.

11 Liebowitz D. Nasopharyngeal carcinoma: the Epstein-Barr virus association. Semin Oncol 1994; 21: 376-381.

12 Fong IW, Ho J, Toy C, Lo B, Fong MW. Value of long-term administration of acyclovir and similar agents for protecting against AIDS-related lymphoma: case-control and historical cohort studies. Clin Infect Dis 2000; 30: 757-761.

13 Lung ML, Lam WK, So SY, Lam WP, Chan KH, Ng MH. Evidence that respiratory tract is major reservoir for Epstein-Barr virus. Lancet 1985; 1: 889-892.

14 Kelly BG, Lok SS, Hasleton PS, Egan JJ, Stewart JP. A rearranged form of Epstein-Barr virus DNA is associated with idiopathic pulmonary fibrosis. Am J Respir Crit Care Med 2002; 166: 510-513.

15 Tang YW, Johnson JE, Browning PJ, et al. Herpesvirus DNA is consistently detected in lungs of patients with idiopathic pulmonary fibrosis. J Clin Microbiol 2003; 41: 2633-2640.

16 Rohde G, Wiethege A, Borg I, et al. Respiratory viruses in exacerbations of chronic obstructive pulmonary disease requiring hospitalisation: a case-control study. Thorax 2003; 58: $37-42$.

17 Seemungal $\mathrm{T}$, Harper-Owen $\mathrm{R}$, Bhowmik $\mathrm{A}$, et al. Respiratory viruses, symptoms, and inflammatory markers in acute exacerbations and stable chronic obstructive pulmonary disease. Am J Respir Crit Care Med 2001; 164: 1618-1623.

18 Stewart JP, Egan JJ, Ross AJ, et al. The detection of EpsteinBarr virus DNA in lung tissue from patients with idiopathic pulmonary fibrosis. Am J Respir Crit Care Med 1999; 159: 1336-1341.

19 Kelly BG, Lok SS, Hasleton PS, Egan JJ, Stewart JP. A rearranged form of Epstein-Barr virus DNA is associated with idiopathic pulmonary fibrosis. Am J Respir Crit Care Med 2002; 166: 510-513.

20 Laviolette M, Carreau M, Coulombe R. Bronchoalveolar lavage cell differential on microscope glass cover. A simple 
and accurate technique. Am Rev Respir Dis 1988; 138: 451-457.

21 Kasahara M, Takahashi Y, Nagata T, et al. Thymidylate synthase expression correlates closely with E2F1 expression in colon cancer. Clin Cancer Res 2000; 6: 2707-2711.

22 Niesters HG, van Esser J, Fries E, Wolthers KC, Cornelissen J, Osterhaus AD. Development of a real-time quantitative assay for detection of Epstein-Barr virus. J Clin Microbiol 2000; 38: 712-715.

23 Gompertz S, O'Brien C, Bayley DL, Hill SL, Stockley RA. Changes in bronchial inflammation during acute exacerbations of chronic bronchitis. Eur Respir J 2001; 17: 1112-1119.

24 Lin JC, Wang WY, Chen KY, et al. Quantification of plasma Epstein-Barr virus DNA in patients with advanced nasopharyngeal carcinoma. N Engl J Med 2004; 350: 24612470 .

25 Haque T, Crawford DH. PCR amplification is more sensitive than tissue culture methods for Epstein-Barr virus detection in clinical material. J Gen Virol 1997; 78: 3357-3360.

26 Wolf H, Bogedain C, Schwarzmann F. Epstein-Barr virus and its interaction with the host. Intervirology 1993; 35: 26-39.

27 Hsu DH, de Waal Malefyt R, Fiorentino DF, et al. Expression of interleukin-10 activity by Epstein-Barr virus protein BCRF1. Science 1990; 250: 830-832.

28 Shao JY, Ernberg I, Biberfeld P, Heiden T, Zeng YX, Hu LF. Epstein-Barr virus LMP1 status in relation to apoptosis, p53 expression and leucocyte infiltration in nasopharyngeal carcinoma. Anticancer Res 2004; 24: 2309-2318.

29 Takata H, Tomiyama H, Fujiwara M, Kobayashi N, Takiguchi M. Cutting edge: expression of chemokine receptor CXCR1 on human effector CD8+ $\mathrm{T}$ cells. J Immunol 2004; 173: 2231-2235.

30 Ince MN, Harnisch B, Xu Z, et al. Increased expression of the natural killer cell inhibitory receptor CD85j/ILT2 on antigen-specific effector CD8 T cells and its impact on CD8 T-cell function. Immunology 2004; 112: 531-542. 